\title{
Decision aids for second-line palliative chemotherapy: a randomised phase II multicentre trial
}

Linda J. M. Oostendorp ${ }^{1}$ (D, Petronella B. Ottevanger ${ }^{2}$, A. Rogier T. Donders ${ }^{1}$, Agnes J. van de Wouw ${ }^{3}$, Ivonne J. H. Schoenaker ${ }^{4}$, Tineke J. Smilde ${ }^{5}$, Winette T. A. van der Graaf ${ }^{2}$ and Peep F. M. Stalmeier ${ }^{1 *}$

\begin{abstract}
Background: There is increasing recognition of the delicate balance between the modest benefits of palliative chemotherapy and the burden of treatment. Decision aids (DAs) can potentially help patients with advanced cancer with these difficult treatment decisions, but providing detailed information could have an adverse impact on patients' well-being. The objective of this randomised phase II study was to evaluate the safety and efficacy of DAs for patients with advanced cancer considering second-line chemotherapy.

Methods: Patients with advanced breast or colorectal cancer considering second-line treatment were randomly assigned to usual care (control group) or usual care plus a DA (intervention group) in a 1:2 ratio. A nurse offered a DA with information on adverse events, tumour response and survival. Outcome measures included patient-reported wellbeing (primary outcome: anxiety) and quality of the decision-making process and the resulting choice.

Results: Of 128 patients randomised, 45 were assigned to the control group and 83 to the intervention group. Median age was 62 years (range 32-81), 63\% were female, and 73\% had colorectal cancer. The large majority of patients preferred treatment with chemotherapy (87\%) and subsequently commenced treatment with chemotherapy (86\%). No adverse impact on patients' well-being was found and nurses reported that consultations in which the DAs were offered went well. Being offered the DA was associated with stronger treatment preferences (3.0 vs. 2.5; $p=0.030$ ) and increased subjective knowledge (6.7 vs. 6.3; $p=0.022$ ). Objective knowledge, risk perception and perceived involvement were comparable between the groups.
\end{abstract}

Conclusions: DAs containing detailed risk information on second-line palliative treatment could be delivered to patients with advanced cancer without having an adverse impact on patient well-being. Surprisingly, the DAs only marginally improved the quality of the decision-making process. The effectiveness of DAs for palliative treatment decisions needs further exploration.

Trial registration: Netherlands Trial Registry (NTR): NTR1113 (registered on 2 November 2007)

Keywords: Breast cancer, Colorectal cancer, Oncology, Decision aids, Palliative chemotherapy, Second-line

\footnotetext{
* Correspondence: peep.stalmeier@radboudumc.nl

'Department for Health Evidence, Radboudumc, Nijmegen, the Netherlands

Full list of author information is available at the end of the article
} 


\section{Background}

While patients with advanced cancer beyond cure are commonly offered palliative chemotherapy, there is increasing recognition of the delicate balance between the modest benefits of palliative chemotherapy and the burden of treatment [1-6]. Survival gains are usually in the range of weeks or months $[7,8]$, and while palliative chemotherapy can relieve symptoms and enhance quality of life [9], receiving palliative chemotherapy near the end of life has also been associated with receiving more aggressive medical care and worse quality of death $[3,10]$. Furthermore, after failure of a first line of chemotherapy given with palliative intent, benefits of further lines of chemotherapy tend to be more limited. Therefore, starting first-line and particularly further-line palliative chemotherapy in addition to best supportive care should be carefully considered and any treatment implemented should be in harmony with the patient's preferences $[5,11,12]$.

Alarmingly, in recent studies from the US, $52 \%$ and $69-$ $81 \%$ of patients receiving palliative chemotherapy seemed to be under the false impression that this treatment may well cure their cancer $[13,14]$. This inaccurate understanding may be related to incomplete communication by the oncologists, as well as patients' inability to accept the incurable nature of their disease [14]. Indeed, there are indications that clinicians and patients purposefully use a strategy of 'collusion' to communicate about the future, including avoiding or delaying the discussion of estimated life expectancy, in an effort to preserve patients' hope [15-19].

Decision aids (DAs) with information about risks and benefits of treatment options can potentially support patients in these difficult treatment choices. There is solid evidence from diverse healthcare settings that DAs can help patients to increase their knowledge and establish realistic expectations, and become more involved in making treatment decisions [20]. While designed to facilitate patient centered care, offering DAs with detailed information about estimated life expectancy for treatment with and without palliative chemotherapy may be at odds with clinicians' and patients' preferred strategy of 'collusion'. Studies have indicated that patients with a worse prognosis usually preferred less information and a less active role in decision-making $[21,22]$, while having prognostic discussions and encouraging patients to become more involved have been shown to be associated with increased anxiety among patients receiving or eligible for palliative chemotherapy [13, 23, 24]. Increased anxiety was also reported by patients who initially welcomed detailed prognostic information [13].

Several DAs have been developed to support decisions about palliative chemotherapy, most of them pertaining to decisions about first-line treatment [25-33]. Encouragingly, this series of mostly pilot studies have generally demonstrated good acceptability, although some patients thought the information was sad or too frank and caused distress or did not promote hope $[25,27,28]$. Beneficial effects included improved knowledge [28, 29, 31, 33] and stronger treatment preferences [30]. In addition, a number of DAs have been developed for advance care planning (i.e. future decisions) in patients with (advanced) cancer [34-37]. Acceptability of these DAs was generally high [35-37] and users demonstrated higher levels of knowledge [37] while their levels of hope and anxiety remained unchanged [35].

The aim of this study is to evaluate the feasibility of offering DAs containing detailed information about estimated life expectancy to patients with advanced breast or colorectal cancer considering second-line palliative chemotherapy, using a randomised multicentre design. Our primary aim was to evaluate any harmful effects of the DAs as compared with usual care, regarding patients' well-being and specifically anxiety. Given patients' potential vulnerability, information was not routinely offered but patients were asked whether they wished to receive detailed information from the DA. In addition, we explored whether the previously reported beneficial effects of DAs also apply to palliative treatment decisions.

\section{Methods}

Study design

This randomised phase II study evaluating the feasibility of decision aids for second-line palliative chemotherapy was conducted in 17 hospitals in the Netherlands. The study was prospectively registered (Netherlands Trial Registry; NTR1113 http://www.trial register.nl/trialreg/admin/rctview.asp?TC=1113), and a detailed account of the study design is available in the study protocol [38] (see Additional file 1). In summary, the decision aid offered information for patients considering second-line palliative chemotherapy for advanced breast or colorectal cancer. To identify patients who would be offered second-line palliative chemotherapy, we approached patients receiving first-line palliative chemotherapy for advanced incurable disease. Patients were excluded in case of a labile personality structure (as assessed by the medical oncologist), a Karnofsky performance score lower than 60, and insufficient Dutch language proficiency.

\section{Recruitment}

Initial screening of potentially eligible patients against the selection criteria was performed by a medical oncologist or nurse. Eligible patients were approached by the health professional to ask permission for a researcher to contact them about a study testing a new way of providing information to patients. Importantly, health professionals did not mention that explicit 
information on expected survival would be offered to patients, in an effort to prevent selection of patients not wishing to receive such information.

\section{Procedure}

When a patient included in the study experienced disease progression and was offered second-line chemotherapy, randomisation was performed. A nurse would open a sealed envelope to find out whether the patient would either: (1) be informed by the oncologist in the usual way (control group); or (2) be informed by the oncologist in the usual way followed by a consultation with a nurse offering a DA (intervention group). Unequal randomisation (using a 1:2 ratio) was used because the sample size of the control group was based on the current evaluation of the DAs, while the sample size of the intervention group was based on more detailed analyses of patients' desire for information [38, 39]. Randomisation lists were computer generated per hospital and tumour type, using a block size of 3 . Patients in the intervention group were offered an appointment with a nurse to receive the DA, typically within a week after the oncologist imparted the news of disease progression and discussed treatment options (depending on local workflow and patient preferences).

\section{The DAs}

The DA booklets were designed based on our previous experience with DAs for prostate cancer treatment [40, 41], and we followed guidance from the International Patient Decision Aids Standards where possible [42]. The booklets started with an introduction describing both treatment options and showing an example of numerical information provided. In the next section, numerical information was provided on: (1) the incidence of adverse events; (2) the chances of achieving a tumour response; and (3) expected median survival. This information was derived from systematic reviews of the literature for the two tumour types $[7,8]$, and tailored to the particular type of chemotherapy offered to the patient (for a total of eleven types of chemotherapy). Figure 1 shows an example of the information shown in a DA for second-line irinotecan; a full copy of a DA is available in Additional file 2.

\section{Measures}

Oncologists completed an inclusion form (see Additional file 3) and nurses completed a brief questionnaire about the interview with the DA (see Additional file 4). Patients were asked to complete a first questionnaire at inclusion (T1) and patients in both groups were asked to complete two follow-up questionnaires one week (T2) and eight weeks (T3) after receiving treatment-related information. Patient questionnaires are available in Additional files 5, 6 and 7.

\section{Sociodemographic variables and medical history}

Patient's gender and tumour type were extracted from the inclusion form. The baseline questionnaire contained questions on age, level of education, marital and working status, and having children or grandchildren.

\section{Intervention interview}

Nurses were given a paper-and-pencil questionnaire divided into two sections (see Additional file 4). The first section was completed during the interview with the patient and started with a question about treatment preference and strength of this preference. After that, the nurse administered the DA.

The nurse first introduced the DA and the two options for second-line treatment (best supportive care with or without second-line palliative chemotherapy) and showed an example of risk information. The nurse then proceeded to offer information for the first item, adverse events. First the patient was given a brief explanation of the type of information to be expected (e.g. implications of a severe adverse event) and then the patient could indicate whether he or she wished to receive the information. The information was provided accordingly. A booklet with information tailored to the patient's desire was available to take home.

To conclude the first section of the interview, the nurse asked the patient once more about treatment preference and strength of this preference. Nurses were instructed to complete the second section after the consultation with the patient. This section included a question about how the interview went, and the nurse was asked to record which chemotherapeutic drug was discussed with the patient.

\section{Outcome measures}

Since this is one of the first randomised studies evaluating the safety and efficacy of a DA in a population of advanced cancer patients deciding about palliative chemotherapy, we decided to explore a broad range of outcomes to assess safety in this potentially vulnerable population, and assess whether the previously found beneficial effects can be replicated in this population. Therefore the selection of outcome measures was largely based on outcomes used in previous research [43].

Given the concerns about anxiety in this potentially vulnerable patient population, the primary outcome of this study was selected to be anxiety. At the time the sample size calculation was conducted, no information was available about the minimal clinically important difference for the HADS anxiety scale. We had to resort to an educated guess and decided to use a difference of 2.2, equivalent to a difference of $>10 \%$ on a scale of $0-21$. Recent studies, albeit in populations of patients with COPD and survivors of acute respiratory failure [44-46], seem to 


\section{ADVERSE EVENTS}

Severe nausea

You are so nauseated that your intake of food and fluid is insufficient

\section{Severe vomiting}

You have to vomit at least 6 times a day sometimes intravenous fluids and intravenous feeding are needed

\section{Severe diarrhoea}

You have an increase of at least 7 stools per day, and may also have problems controlling your bowels

\section{Severe hair loss}

You lose all your hair (on your head)

\section{Death}

You die as a result of a severe adverse event

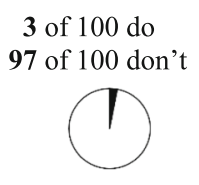

8 of 100 do

92 of 100 don't

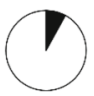

6 of 100 do

94 of 100 don't

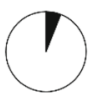

0 of 100 do 100 of 100 don't

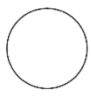

0 of 100 do 100 of 100 don't

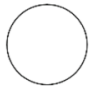

\section{RESPONSE OF THE CANCER}

The size of the cancer is reduced (white) The size of the cancer remains stable (stripes) The size of the cancer is increased (black)

\section{0 of 100}

6 of 100

94 of 100

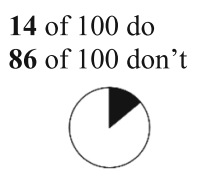

14 of 100 do 86 of 100 don't

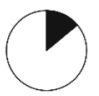

22 of 100 do 78 of 100 don't

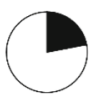

44 of 100 do $\mathbf{5 6}$ of 100 don't

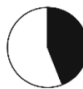

1 of 100 does 99 of 100 don't

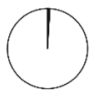

4 of 100

52 of 100

44 of 100

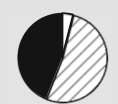

9 months

\section{SURVIVAI}

After this number of months 50 out of 100 people are still alive and 50 out of 100 people will have died

Fig. 1 Example of a summary page of a DA for colorectal cancer

indicate that the estimate of 2.2 was not unreasonable. The primary outcome measure anxiety was defined a priori, and all main and additional outcome measures have been described beforehand in the publicly available study protocol [38]. The outcomes of our exploratory analysis of additional outcome measures were interpreted with appropriate caution, and any statistically significant findings will need to be confirmed by future studies [47]. An overview of outcome measures and operationalisation is shown in Table 1.

Main outcome measures The primary outcome measure of this study was anxiety [48]. Four other measures of patient well-being were used, including general health, health-related quality of life (HRQoL) [49], depression [48], and cancer worries [50].

\section{Additional outcome measures \\ Coping}

Patients were asked questions on their mental adjustment to cancer, including their style of coping including helplessness/hopelessness, fighting spirit, and avoidance [51]. In addition, patients were asked questions on perceived participation and perceived involvement including the perception of being offered a choice and the perception that their opinion mattered $[52,53]$. 
Table 1 Overview of outcome measures

\begin{tabular}{|c|c|c|}
\hline & & Timing of measurements ${ }^{1}$ \\
\hline Measures & Operationalisation & $\begin{array}{l}\text { Baseline } \\
\mathrm{T} 1\end{array}$ \\
\hline
\end{tabular}

Main outcome measures

Well-being

Anxiety $^{2}$

Depression

General health

Hospital Anxiety and Depression Scale

Hospital Anxiety and Depression Scale

Cancer Worries

0-10 (worst-best imaginable)

Health-related quality of life

Adapted Lerman's Cancer Worry Scale

EORTC QLQ-C15-PAL

$\begin{array}{ccc}x & x & x \\ x & x & x \\ x & x & x \\ x & x & x\end{array}$

Additional outcome measures

Coping

Helplessness/hopelessness

Fighting spirit

Avoidance

Perceived participation

Perceived involvement

Information-related measures

Amount of information

Undesired information

Satisfaction with quality of information

Balanced presentation of information

Evaluation of information

Mental Adjustment to Cancer Scale

Mental Adjustment to Cancer Scale

Mental Adjustment to Cancer Scale

Problem-Solving Decision Making Scale

yes/no

1-7 (I received way too little-way too much information)

$x$

yes/no

1-6 (not satisfied-very much satisfied)

1-5 (clearly in favour of chemotherapy plus BSC -

clearly in favour of BSC alone)

1-5 (no negative experience-very negative experience)

\section{$x$}

$x$

$x$

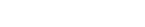

$x$

1-10 (extremely poor-excellent)

five statements to be judged as right or wrong

1-5 (very high-very low) ${ }^{3}$

1-7 (much higher-much lower) ${ }^{4}$

$0-100 \%^{5}$

Decision Evaluation Scales

Decision Evaluation Scales

Decision Evaluation Scales

chemotherapy + BSC /BSC alone/don't know

1-5 (not strong-very strong) ${ }^{6}$

1-10 (extremely poor-excellent)

1-6 (dissatisfied-very satisfied) $x$

Decision-related measures

Decision satisfaction-uncertainty

Weighing pros and cons

Treatment choice

Strength of treatment preference

Treatment attitudes

Valuations
Treatment satisfaction

Abbreviation: BSC best supportive care

${ }^{1}$ Baseline: at inclusion; follow-up: 1 and 8 weeks after receiving the treatment-related information

${ }^{2}$ Anxiety is the primary outcome measure

${ }^{3}$ Question 1: 'the chance of experiencing an adverse event'

${ }^{4}$ Question 2: 'the chance of experiencing a beneficial effect on the tumour when having treatment with chemotherapy and BSC, as compared with

BSC alone' and question 3 'the chance of experiencing pain when having treatment with chemotherapy and BSC, as compared with BSC alone'

${ }^{5}$ The absolute deviation between patient's objective risk perception and the actual risk (as identified in the literature reviews [7, 8] and presented in

the DAs) was calculated.

${ }^{6}$ For patients whose treatment choice was 'undecided', the strength of the treatment preference was scored as zero 


\section{Information-related measures}

Questions were asked about the amount of treatmentrelated information received and about receiving any undesired information. Furthermore, patients were asked to rate the quality of information, whether treatment options were presented in a balanced way, and whether they had any negative experiences with the information received.

\section{Knowledge}

Patients rated their knowledge about cancer and its treatment, and were presented with five statements, judged to be right or wrong, to assess objective knowledge. For subjective risk perception, patients were asked to rate the following chances: (1) the chance of experiencing an adverse event, (2) the chance of experiencing a beneficial effect on the tumour when having treatment with chemotherapy and BSC, as compared with BSC alone, and (3) the chance of suffering from pain when opting for chemotherapy, as compared with BSC alone. Objective risk perception was assessed by asking for the chances of: (1) experiencing severe diarrhoea and (2) achieving partial or complete tumour response. The format of these questions was mostly based on knowledge questions in other studies [20] and our own previous work $[40,41]$ and the content was informed by key information provided in the decision aid, e.g. adverse events and tumour response.

\section{Decision-related measures}

The decision was evaluated with questions about patients' satisfaction and uncertainty around the decision, patients' sense of control in the treatment decision, and deliberation of pros and cons of treatment options [54]. Furthermore, patients were asked about their preferred treatment, and, if applicable, the strength of that preference (T2), and about the treatment they actually received (T3).

\section{Treatment attitudes}

Patients were asked about treatment attitudes because these are considered to be one of the main determinants of (health) behaviour, according to theories for behaviour and behaviour change [55]. Patients were asked to value each of the two treatment options on a scale of 1-10 (T2 and T3), and rate their satisfaction with (1) the implemented treatment; (2) the physical consequences of treatment and (3) the emotional consequences of treatment (1 'dissatisfied' - 6 'very satisfied') at T3.

\section{Statistical Analysis}

To assess the risk of attrition bias, characteristics of randomised patients were compared with inadvertently non-randomised patients, using independent samples t-tests or Chi-Square tests, as applicable. The safety and efficacy of the DAs were assessed by comparing patients in the intervention and control groups, on an intentionto-treat basis. Nominal variables were analysed using the
Chi-Square test of independence. Interval variables that were available for a single follow-up measurement were analysed using an independent samples t-test, Chi-Square test of independence or Fisher Exact Test or, if a baseline measurement was available, analysis of covariance (ANCOVA). Interval variables that were available for both follow-up measurements were analysed using linear mixed models. In these models, dependent variables were the two follow-up measurements (T2 and T3), and covariates were the variables 'group', 'time', an interaction term between 'group' and 'time' and if available, 'baseline measurement'. The covariates 'group"time', 'time', and 'baseline measurement' were stepwise removed from the model based on statistical significance. To accommodate the repeated measures we used a heterogeneous compound symmetry error structure.

\section{Results}

Patients

Screening of potentially eligible patients took place between February 2008 and April 2012. As shown in Fig. 2, out of 441 patients screened, 34 patients (8\%) were not approached by the oncologist and therefore the selection criteria could not be verified. Another 86 patients $(20 \%)$ did not fulfil the selection criteria. Out of the remaining 321 patients, $263(82 \%)$ agreed to participate and gave informed consent.

Over time, 171 included patients (65\%) faced the decision on second-line treatment and were eligible for randomisation. However, 43 of them (16\%) were not randomised and dropped out of the study. To assess selective attrition, we compared characteristics between these 43 patients and the 128 patients who were randomised and found that patients were similar with regard to gender, age, education, tumour type, information preference and general health.

Out of 128 patients randomised, 45 were randomly assigned to the control group and 83 were assigned to receiving the DA in addition to usual care. Characteristics of randomised patients are shown in Table 2. The two groups were similar with regard to baseline characteristics.

\section{Intervention interview}

In the intervention group, 77 patients (93\%) completed the intervention interview with a nurse offering the DA. A total of 20 nurses (between 1 and 3 per hospital) were involved in conducting the intervention interviews (median number of interviews conducted: 2; range 1-22). The majority opted to be shown the information in the DA with regard to (1) adverse events (96\%); (2) tumour response (91\%); and (3) survival (74\%). Nurses felt that $90 \%$ of the interviews went (very) well. 


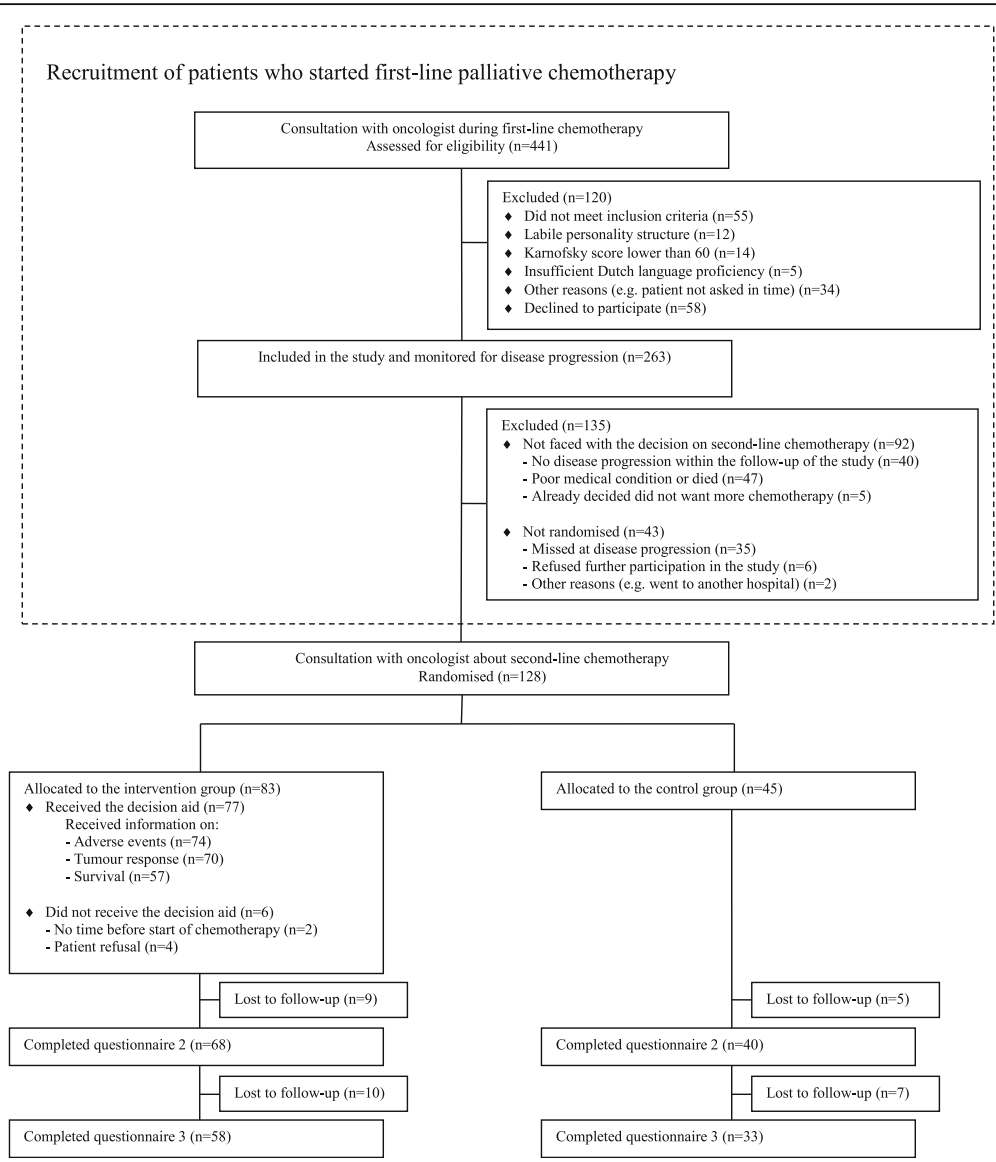

Fig. 2 Flow diagram

\section{Outcomes}

Table 3 provides a comparison of outcomes for the main outcome measures and additional outcomes measured at both follow-up moments (T2 and T3), analysed using linear mixed models. The variable 'group' was retained in all models to assess the effect of the DA. Table 4

Table 2 Patient characteristics

\begin{tabular}{lll}
\hline & $\begin{array}{l}\text { Intervention } \\
\text { group } \\
(\mathrm{n}=83)\end{array}$ & $\begin{array}{l}\text { Control } \\
\text { group } \\
(\mathrm{n}=45)\end{array}$ \\
\hline Male gender, n (\%) & $31(37 \%)$ & $16(36 \%)$ \\
Age, mean (SD) & $61(9.1)$ & $62.5(9.5)$ \\
Living with partner, n (\%) & $64(77 \%)$ & $37(82 \%)$ \\
Employed, $\mathrm{n}(\%)$ & $25(30 \%)$ & $13(29 \%)$ \\
Having children, $\mathrm{n}(\%)$ & $74(89 \%)$ & $38(84 \%)$ \\
Having grandchildren, n (\%) & $44(53 \%)$ & $26(58 \%)$ \\
College education or more, n (\%) & $24(29 \%)$ & $7(16 \%)$ \\
Tumour characteristics & & $32(71 \%)$ \\
Colorectal cancer, $n$ (\%) & $61(73 \%)$ & $13(29 \%)$ \\
Breast cancer, $n$ (\%) & $22(27 \%)$ & \\
\hline
\end{tabular}

provides a comparison of additional outcomes between groups at a single follow-up moment (T2 or T3).

\section{Main outcome measures}

Receiving the DA was not related to any of the measures for well-being, including the primary outcome anxiety (Table 3). In both groups, average anxiety scores were approximately 6 on a $0-21$ scale, and the difference between the groups was -0.1 (95\% CI $-1.1 ; 0.9)$. When using a threshold of 8 or 11 [56], heightened levels of anxiety and/or depression were detected in $6-33 \%$ of all patients at $\mathrm{T} 1,10-38 \%$ of patients at $\mathrm{T} 2$ and $10-33 \%$ of patients at T3, which is similar to other populations of patients with advanced cancer.

\section{Additional outcome measures}

Coping Patients in the intervention and control groups reported equal levels of helplessness/hopelessness, fighting spirit, avoidance, and perceived participation (Table 3) and perceived involvement (Table 4). 
Table 3 Comparison of outcomes over multiple time points (T2 and T3)

\begin{tabular}{|c|c|c|c|c|c|c|}
\hline \multirow{2}{*}{ Measure (answer scale) $^{1}$} & & \multicolumn{5}{|c|}{ Linear mixed models } \\
\hline & & $\begin{array}{l}\text { Intervention group }{ }^{2} \\
\text { Mean (SD) }\end{array}$ & $\begin{array}{l}\text { Control group } \\
\text { Mean (SD) }\end{array}$ & $\begin{array}{l}\text { Covariates } \\
\text { in model }\end{array}$ & $\begin{array}{l}\text { Difference between intervention and } \\
\text { control group averaged } \\
\text { over } \mathrm{T} 2 \text { and } \mathrm{T} 3, \\
\text { adjusted for } \mathrm{T}^{3} \\
(95 \% \mathrm{Cl})\end{array}$ & $\begin{array}{l}\text { Two- sided } \\
p \text { value }\end{array}$ \\
\hline \multicolumn{7}{|l|}{ Main outcome measures } \\
\hline \multicolumn{7}{|l|}{ Well-being } \\
\hline \multirow[t]{3}{*}{ Anxiety $^{4}(0-21)$} & $\mathrm{T} 1$ & $5.7(4.0)$ & $5.6(4.0)$ & Group & $-0.1(-1.1 ; 0.9)$ & 0.808 \\
\hline & $\mathrm{T} 2$ & $6.6(4.5)$ & $6.1(4.5)$ & Baseline & & \\
\hline & $\mathrm{T} 3$ & $5.5(4.1)$ & $5.9(4.6)$ & Time & & \\
\hline \multirow[t]{3}{*}{ Depression (0-21) } & $\mathrm{T} 1$ & $5.1(3.6)$ & $4.1(3.0)$ & Group & $-0.7(-1.7 ; 0.3)$ & 0.142 \\
\hline & $\mathrm{T} 2$ & $5.6(4.2)$ & $5.6(4.2)$ & Baseline & & \\
\hline & $\mathrm{T} 3$ & $5.3(3.6)$ & $5.2(3.5)$ & & & \\
\hline \multirow[t]{3}{*}{ General health (0-10) } & $\mathrm{T} 1$ & $6.5(1.6)$ & $7.1(1.7)$ & Group & $-0.2(-0.8 ; 0.5)$ & 0.615 \\
\hline & $\mathrm{T} 2$ & $5.7(1.8)$ & $6.1(1.9)$ & Baseline & & \\
\hline & $\mathrm{T} 3$ & $5.8(2.0)$ & $5.9(1.7)$ & & & \\
\hline \multirow[t]{3}{*}{ Cancer worries (1-4) } & $\mathrm{T} 1$ & $2.1(0.6)$ & $2.0(0.6)$ & Group & $-0.1(-0.3 ; 0.1)$ & 0.192 \\
\hline & $\mathrm{T} 2$ & $2.1(0.5)$ & $2.1(0.6)$ & Baseline & & \\
\hline & $\mathrm{T} 3$ & $2.1(0.6)$ & $2.2(0.7)$ & & & \\
\hline \multirow[t]{3}{*}{ HRQoL: physical functioning (0-100) } & $\mathrm{T} 1$ & $75.2(22.3)$ & $79.2(18.1)$ & Group & $-2.2(-9.2 ; 4.8)$ & 0.536 \\
\hline & $\mathrm{T} 2$ & $68.2(22.5)$ & $72.3(21.0)$ & Baseline & & \\
\hline & $\mathrm{T} 3$ & $67.9(25.0)$ & $71.1(22.1)$ & & & \\
\hline \multirow[t]{3}{*}{ HRQoL: emotional functioning (0-100) } & $\mathrm{T} 1$ & $81.0(22.0)$ & $80.5(20.2)$ & Group & $3.5(-3.4 ; 10.5)$ & 0.318 \\
\hline & $\mathrm{T} 2$ & $74.3(22.0)$ & $73.6(27.1)$ & Baseline & & \\
\hline & $\mathrm{T} 3$ & $79.7(20.2)$ & $75.5(25.2)$ & & & \\
\hline \multicolumn{7}{|l|}{ Additional outcome measures } \\
\hline \multicolumn{7}{|l|}{ Coping } \\
\hline \multirow[t]{3}{*}{ Helplessness/Hopelessness (1-4) } & $\mathrm{T} 1$ & $1.8(0.6)$ & $1.7(0.5)$ & Group & $0.0(-0.1 ; 0.2)$ & 0.759 \\
\hline & $\mathrm{T} 2$ & $1.8(0.6)$ & $1.8(0.5)$ & Baseline & & \\
\hline & $\mathrm{T} 3$ & $1.9(0.6)$ & $1.8(0.5)$ & & & \\
\hline \multirow[t]{3}{*}{ Fighting Spirit (1-4) } & $\mathrm{T} 1$ & $2.9(0.6)$ & $3.2(0.6)$ & Group & $-0.0(-0.2 ; 0.1)$ & 0.568 \\
\hline & $\mathrm{T} 2$ & $2.7(0.6)$ & $3.0(0.6)$ & Baseline & & \\
\hline & $\mathrm{T} 3$ & $2.8(0.7)$ & $2.8(0.7)$ & & & \\
\hline \multirow[t]{3}{*}{ Avoidance (1-4) } & $\mathrm{T} 1$ & $2.5(0.7)$ & $2.6(0.8)$ & Group & $0.1(-0.0 ; 0.3)$ & 0.094 \\
\hline & $\mathrm{T} 2$ & $2.5(0.7)$ & $2.6(0.7)$ & Baseline & & \\
\hline & $\mathrm{T} 3$ & $2.5(0.7)$ & $2.3(0.7)$ & & & \\
\hline \multirow[t]{2}{*}{ Perceived participation (1-5) } & $\mathrm{T} 2$ & $3.1(1.0)$ & $2.8(0.9)$ & Group & $0.2(-0.2 ; 0.5)$ & 0.395 \\
\hline & $\mathrm{T} 3$ & $2.9(1.0)$ & $2.9(0.8)$ & & & \\
\hline \multicolumn{7}{|l|}{ Information-related measures } \\
\hline \multirow[t]{3}{*}{ Amount of information received (1-7) } & $\mathrm{T} 1$ & $3.8(0.6)$ & $3.9(0.3)$ & Group & $-0.1(-0.3 ; 0.0)$ & 0.157 \\
\hline & $\mathrm{T} 2$ & $3.8(0.7)$ & $4.0(0.4)$ & Baseline & & \\
\hline & $\mathrm{T} 3$ & $3.8(0.5)$ & $3.9(0.3)$ & & & \\
\hline \multicolumn{7}{|l|}{ Satisfaction with quality of information (1-6) } \\
\hline Severe adverse events & $\mathrm{T} 2$ & $4.8(0.9)$ & $4.8(1.0)$ & Group & $0.0(-0.3 ; 0.4)$ & 0.802 \\
\hline
\end{tabular}


Table 3 Comparison of outcomes over multiple time points (T2 and T3) (Continued)

\begin{tabular}{|c|c|c|c|c|c|c|}
\hline & $\mathrm{T} 3$ & $4.5(1.2)$ & $4.4(1.1)$ & Time & & \\
\hline \multirow[t]{2}{*}{ Tumour response } & $\mathrm{T} 2$ & $4.5(1.0)$ & $4.4(1.2)$ & Group & $0.1(-0.2 ; 0.5)$ & 0.536 \\
\hline & $\mathrm{T} 3$ & $4.3(1.1)$ & $4.2(1.1)$ & & & \\
\hline \multirow[t]{2}{*}{ Survival } & $\mathrm{T} 2$ & $4.0(1.3)$ & $4.0(1.3)$ & Group & $0.1(-0.3 ; 0.6)$ & 0.540 \\
\hline & $\mathrm{T} 3$ & $4.0(1.2)$ & $3.6(1.4)$ & & & \\
\hline \multicolumn{7}{|l|}{ Knowledge } \\
\hline \multirow[t]{2}{*}{ Subjective knowledge ${ }^{5}$} & $\mathrm{~T} 1$ & $6.5(1.2)$ & $6.6(1.0)$ & Group & $0.5(0.1 ; 0.9)$ & 0.022 \\
\hline & T2 & $6.7(1.2)$ & $6.3(1.3)$ & Baseline & & \\
\hline \multicolumn{7}{|l|}{ Decision-related measures } \\
\hline \multirow[t]{2}{*}{ Decision satisfaction-uncertainty (1-5) } & $\mathrm{T} 2$ & $4.1(0.6)$ & $4.0(0.7)$ & Group & $0.1(-0.1 ; 0.3)$ & 0.155 \\
\hline & T3 & $4.1(0.6)$ & $3.9(0.4)$ & & & \\
\hline \multirow[t]{2}{*}{ Decision control (1-5) } & $\mathrm{T} 2$ & $4.2(0.7)$ & $4.3(0.6)$ & Group & $-0.1(-0.3 ; 0.2)$ & 0.617 \\
\hline & $\mathrm{T} 3$ & $4.3(0.6)$ & $4.3(0.6)$ & & & \\
\hline \multirow[t]{2}{*}{ Weighing pros and cons (1-5) } & $\mathrm{T} 2$ & $4.2(0.8)$ & $3.9(1.0)$ & Group & $0.2(-0.1 ; 0.5)$ & 0.118 \\
\hline & T3 & $4.0(1.1)$ & $3.8(0.8)$ & & & \\
\hline \multicolumn{7}{|l|}{ Treatment attitudes toward both options } \\
\hline \multirow[t]{2}{*}{ Valuations: chemotherapy + BSC (1-10) } & $\mathrm{T} 2$ & $7.5(1.7)$ & $7.2(1.6)$ & Group & $0.1(-0.5 ; 0.7)$ & 0.677 \\
\hline & T3 & $7.1(1.8)$ & $7.3(1.7)$ & & & \\
\hline \multirow[t]{2}{*}{ Valuations: BSC alone (1-10) } & $\mathrm{T} 2$ & $3.7(2.1)$ & $4.3(2.1)$ & Group & $-0.4(-1.2 ; 0.3)$ & 0.246 \\
\hline & T3 & $4.1(2.3)$ & 4.6 (2.4) & & & \\
\hline
\end{tabular}

Information-related measures No differences were found between the groups over time for the amount of information and satisfaction with the quality of information (Table 3). Patients in both groups responded similarly to questions about undesired information, balanced presentation, and evaluation of the information (Table 4).

Knowledge Patients in the intervention group felt significantly more knowledgeable compared with patients in the control group (6.7 vs. 6.3; $\mathrm{p}=0.022)$. Objective knowledge and subjective and objective risk perceptions were similar between the groups (Table 4).

Decision-related measures At the first follow-up (T2) the large majority of patients reported having a treatment preference (95\%); most of them favoured chemotherapy $(87 \%)$. The two groups responded similarly to questions about decision satisfaction and uncertainty, decision control, and weighing of pros and cons (Table 3). Patients in the intervention group reported stronger treatment preferences (3.0 vs. $2.5 ; \mathrm{p}=0.030)$. At $\mathrm{T} 3$, there were no differences in treatment received between the groups (Table 4).
Treatment attitudes Valuations of both treatment options were comparable between the groups (Table 3). In both groups, treatment with chemotherapy was on average valued with a 7.4 while treatment with BSC alone was valued with a 4.0 (on a scale of 1-10), resulting in a mean difference of 3.4 (95\% CI 2.8-4.1; $\mathrm{p}=0.000)$. As shown in Table 4, patients in both groups felt equally satisfied with their treatment and the consequences of treatment (both physical and emotional).

\section{Discussion}

This study was designed to address concerns about offering detailed treatment-related information to a potentially vulnerable group of patients with advanced cancer $[13,18,19,23]$. In line with previous research in a wide variety of patient populations [20] and patients with advanced cancer in an earlier stage of the treatment trajectory [25, 33, 57], this study has not revealed an adverse impact of decision aids in this patient population. The large majority of patients opted to be shown all of the available detailed information in the decision aid and nurses reported that nearly all consultations went well. Follow-up at 1 and 8 weeks did not reveal any harmful effects on anxiety or other measures of well-being, 
Table 4 Comparison of outcomes at a single time point (T2 or T3)

\begin{tabular}{|c|c|c|c|}
\hline Measure (answer scale) $^{1}$ & $\begin{array}{l}\text { Intervention group } \\
\mathrm{N}(\%) \text { or mean (SD) }\end{array}$ & $\begin{array}{l}\text { Control group } \\
\mathrm{N}(\%) \text { or mean (SD) }\end{array}$ & $p$ value \\
\hline A dditional outcome measures: measurements at T2 & $n=68$ & $\mathrm{n}=40$ & \\
\hline \multicolumn{4}{|l|}{ Coping: Involvement } \\
\hline Perceived involvement: perception of being offered a choice $(y e s / n o)^{2}$ & $45(66 \%)$ & $26(67 \%)$ & 0.959 \\
\hline Perceived involvement: perception whether patient's opinion mattered (yes/no) ${ }^{2}$ & $51(75 \%)$ & $30(77 \%)$ & 0.823 \\
\hline \multicolumn{4}{|l|}{ Information-related measures } \\
\hline Undesired information (yes/no) & $6(10 \%)$ & $7(18 \%)$ & 0.244 \\
\hline Balanced presentation of information (1-5) & $2.7(0.7)$ & $2.4(1.1)$ & 0.201 \\
\hline Evaluation of information on treatment options: unpleasant (1-5) & $2.1(1.0)$ & $2.2(1.2)$ & 0.679 \\
\hline Evaluation of information on treatment options: shocking (1-5) & $2.3(1.0)$ & $2.3(1.0)$ & 0.958 \\
\hline Evaluation of information on treatment options: frightening (1-5) & $2.4(0.9)$ & $2.2(1.0)$ & 0.347 \\
\hline Evaluation of information on severe adverse events: threatening (1-5) & $2.5(1.0)$ & $2.7(1.1)$ & 0.358 \\
\hline Evaluation of information on tumour response: threatening (1-5) & $2.7(1.1)$ & $2.7(1.0)$ & 0.786 \\
\hline Evaluation of information on survival: threatening (1-5) & $3.0(1.3)$ & $2.6(1.3)$ & 0.112 \\
\hline \multicolumn{4}{|l|}{ Knowledge } \\
\hline Objective knowledge (1-5) & $3.4(1.3)$ & $3.5(1.3)$ & 0.684 \\
\hline Subjective risk perception: severe adverse events (1-5) & $2.2(0.7)$ & $2.0(0.8)$ & 0.242 \\
\hline Subjective risk perception: tumour response (1-7) & $1.8(1.1)$ & $2.1(1.1)$ & 0.219 \\
\hline Subjective risk perception: pain (1-7) & $3.0(1.2)$ & $3.2(1.3)$ & 0.461 \\
\hline Objective risk perception: diarrhoea (0-100\%) $)^{3}$ & $30.9(22.1)$ & $34.9(22.1)$ & 0.366 \\
\hline Objective risk perception: tumour response $(0-100 \%)^{3}$ & $30.0(20.8)$ & $32.5(14.3)$ & 0.463 \\
\hline \multicolumn{4}{|l|}{ Decision-related measures } \\
\hline Treatment choice: undecided (vs. decided) & $1(2 \%)$ & $4(10 \%)$ & 0.068 \\
\hline Treatment choice: chemotherapy (vs. no chemotherapy) & $63(96 \%)$ & $31(84 \%)$ & 0.067 \\
\hline Strength of treatment preference (1-5) & $3.0(1.0)$ & $2.5(1.2)$ & 0.030 \\
\hline Additional outcome measures: measurements at T3 & $\mathrm{n}=58$ & $\mathrm{n}=33$ & \\
\hline \multicolumn{4}{|l|}{ Coping: Involvement } \\
\hline Perceived involvement: perception of being offered a choice (yes/no $)^{2}$ & $41(71 \%)$ & $20(61 \%)$ & 0.299 \\
\hline Perceived involvement: perception whether patient's opinion mattered (yes/no) ${ }^{2}$ & $47(81 \%)$ & $25(76 \%)$ & 0.525 \\
\hline \multicolumn{4}{|l|}{ Decision-related measures } \\
\hline Treatment received: chemotherapy and BSC (vs. BSC alone) & $50(88 \%)$ & $26(84 \%)$ & 0.746 \\
\hline \multicolumn{4}{|l|}{ Treatment attitudes toward the treatment received } \\
\hline Treatment satisfaction: received treatment (1-6) & $4.6(1.3)$ & $4.6(1.0)$ & 0.794 \\
\hline Treatment satisfaction: physical consequences of treatment (1-6) & $3.8(1.5)$ & $3.5(1.3)$ & 0.372 \\
\hline Treatment satisfaction: emotional consequences of treatment (1-6) & $4.0(1.4)$ & $3.9(1.3)$ & 0.725 \\
\hline
\end{tabular}

Abbreviation: BSC best supportive care

${ }^{1}$ More information on the scales can be found in Table 1

${ }^{2}$ Measured at $\mathrm{T} 2$ and $\mathrm{T} 3$

${ }^{3}$ Objective risk perception represents the absolute deviance between patient's risk perception and actual risk as presented in the DA, based on literature reviews $[7,8]$

including cancer worries, nor was receiving the decision aid associated with having received undesired information, reporting a more negative experience (e.g. receiving threatening or frightening information), or increased feelings of hopelessness.

With regard to efficacy, patients who were offered a DA were found to have better subjective knowledge and stronger treatment preferences. These are important benefits. However, previous studies had also reported beneficial effects regarding objective knowledge, risk perception, and involvement in decision-making [40, 41, 58-60] and these could not be confirmed. The question arises why these benefits could not be confirmed in our study. Several explanations are possible, and might be 
related to: (1) the population of patients with advanced cancer considering second-line palliative chemotherapy; (2) the decision aids; or (3) the design of our trial.

First, in our interpretation, a similar relative absence of effects was reported in the single randomised study evaluating a DA on first-line palliative chemotherapy; a positive effect was reported for objective knowledge, but no positive effects were found for other commonly used measures such as involvement [33]. Therefore, we might contribute the absence of effects to the particular characteristics of the population of vulnerable patients with advanced cancer. Perhaps these patients did not perceive the option to refrain from active treatment as a realistic option. This has been suggested before [5, 61-64]. Also data from our trial seem to suggest so, as patients valued the appropriateness of best supportive care alone significantly lower than best supportive care with chemotherapy. Furthermore, a number of patients wrote down open-ended comments on the patient questionnaires, including 'I cannot value the appropriateness of BSC, because I have not discussed it or thought about it', 'I do not have a choice', and 'The only thing that matters is the effect of chemotherapy, adverse events do not matter to me'. Previous research has shown that particularly for second-line treatment, an important reason to opt for active treatment is to promote hope [62-64].

Second, the DAs were offered by 20 different nurses and after the consultation with the oncologist; timing was tailored to local workflows and DAs may have been offered relatively late in the decision-making process, which may have reduced their value. It could also be hypothesized that the added value of the DAs was reduced because all patients in this study had previous experience with chemotherapy. Third, another explanation could be related to a lack of statistical power of this study since power was reduced by patient attrition at $\mathrm{T} 2$ and T3, however none of the differences between the groups appears large enough to be clinically relevant.

One of the strengths of this study is that we performed one of the few randomised evaluations of a DA for palliative chemotherapy, and the first exploratory evaluation for second-line treatment options. A further strength is that we facilitated generalisability of the results by recruiting patients from a large number of hospitals, recruiting patients receiving first-line chemotherapy while applying broad selection criteria, and achieving an $82 \%$ informed consent rate. Thorough attention was paid to including evidence-based information in the DAs, by performing systematic reviews which were subjected to peer-review $[7,8]$.

Noteworthy limitations include multiple testing. A total of 52 comparisons between the intervention and control group were performed, of which two (4\%) reached statistical significance at the level $\mathrm{p}<0.05$. These two findings need to be interpreted with caution. Another limitation inherent to the nature of DAs is that complete blinding was not possible. Nevertheless, oncologists were not aware of the allocation prior to randomisation and our analysis showed no differences in clinical and sociodemographic characteristics between randomised and non-randomised patients.

Future studies might explore patients' perceptions of palliative treatment choices, including ways to make patients aware that best supportive care without chemotherapy is a realistic treatment option. Studies might aim to close the decision support loop by scheduling a consultation with the oncologist after the DA is offered. This allows patients time to think and have an informed discussion with their oncologist. With regard to the presentation of survival information, developers of future DAs should consider offering patients survival information using typical, best-case and worst-case scenarios instead of median survival [65].

\section{Conclusions}

Decision aids with detailed information on risks and benefits of second-line palliative chemotherapy were welcomed by the majority of patients with advanced cancer and no adverse impact on patient well-being was observed. These decision support tools can help to provide standardised information about potential risks and benefits of available treatment options. While patients reported some beneficial effects, other previously reported benefits -including improvements in objective knowledge, risk perception and involvement in decisionmaking- were not confirmed for the decision aids in this study. Results from this explorative trial have indicated that even in a potentially vulnerable population of patients with advanced cancer beyond cure, decision aids with detailed treatment-related information can be offered, and this encouraging finding will hopefully stimulate further research in this field.

\section{Additional files}

Additional file 1: Changes from published study protocol. Overview of changes in study design compared with the published protocol (PDF $640 \mathrm{~kb}$ )

Additional file 2: Decision aid for second-line irinotecan. Example of information provided in a decision aid. (PDF $89 \mathrm{~kb}$ )

Additional file 3: Inclusion and progression form. Copy of questionnaire completed by clinicians at inclusion and progression. (PDF $79 \mathrm{~kb}$ )

Additional file 4: Questionnaire decision aid. Copy of nurse questionnaire. (PDF $89 \mathrm{~kb}$ )

Additional file 5: Patient questionnaire 1. Copy of patient questionnaire 1 (T1, baseline). (PDF 236 kb)

Additional file 6: Patient questionnaire 2. Copy of patient questionnaire 2 (T2, one week follow-up). (PDF 402 kb) 
Additional file 7: Patient questionnaire 3. Copy of patient questionnaire 3 (T3, eight week follow-up). (PDF $103 \mathrm{~kb}$ )

\author{
Abbreviations \\ ANCOVA: Analysis of covariance; BSC: Best supportive care; Cl: Confidence \\ interval; DA: Decision aid; NTR: Netherlands Trial Registry; SD: Standard \\ deviation
}

\section{Acknowledgements}

The authors are grateful to all patients and health professionals for investing their precious time in this study. Patients were accrued by clinicians at the Medical Centre Alkmaar, the Jeroen Bosch Hospital in Den Bosch; the Slingeland Hospital in Doetinchem; the Catharina Hospital in Eindhoven; the Medical Spectrum Twente in Enschede, the St. Anna Hospital in Geldrop, the University Medical Centre Groningen in Groningen; the St Jansdal Hospital in Harderwijk; the Elkerliek Hospital in Helmond; the Medical Centre Leeuwarden; the Radboud University Medical Centre in Nijmegen; the Bernhoven Hospital in Oss; the St. Antonius Hospital in Nieuwegein and Utrecht; the Bernhoven Hospital in Veghel; the Máxima Medical Centre in Veldhoven; VieCuri Medical Centre in Venlo/Venray; and the Isala Clinics in Zwolle. Eva Volmeijer, Mirte Sprengers, and Sanne Hobbelink are thanked for their assistance with the data collection.

\section{Funding}

This work was supported by the Dutch Cancer Society [grant number KUN 2006-3465]. The funder had no role in the design of the study and collection, analysis, and interpretation of data and in writing the manuscript.

\section{Availability of data and materials}

The dataset used during the current study is available from the corresponding author on reasonable request.

\section{Authors' contributions}

PS and PO conceived of the study. LO, PS, PO, WG, RD contributed to the design of the study. LO, PS, PO, AW, IS, TS contributed to data collection. LO, PS, PO, WG, RD conducted data analysis and interpretation. LO and PS drafted the first version of the manuscript with early involvement by PO and WG. All authors critically revised the manuscript and approved the final version of the manuscript.

\section{Ethics approval and consent to participate}

Ethical approval was obtained from the regional ethics review committee (CMO Arnhem-Nijmegen) as well as the research ethics committees of all participating hospitals. All patients included in the study provided written informed consent. Obtaining informed consent from health professionals was not required according to local regulations.

\section{Consent for publication}

Not applicable

\section{Competing interests}

The authors declare that they have no competing interests.

\section{Publisher's Note}

Springer Nature remains neutral with regard to jurisdictional claims in published maps and institutional affiliations.

\section{Author details}

'Department for Health Evidence, Radboudumc, Nijmegen, the Netherlands. ${ }^{2}$ Department of Medical Oncology, Radboudumc, Nijmegen, the Netherlands. ${ }^{3}$ Department of Internal Medicine, VieCuri Medical Centre, Venlo, the Netherlands. ${ }^{4}$ Department of Internal Medicine, Isala Clinics, Zwolle, the Netherlands. ${ }^{5}$ Department of Medical Oncology, Jeroen Bosch Hospital, Den Bosch, the Netherlands.
Received: 25 January 2017 Accepted: 21 August 2017

Published online: 31 August 2017

\section{References}

1. Harrington SE, Smith TJ. The role of chemotherapy at the end of life: "when is enough, enough?". JAMA. 2008;299(22):2667-78.

2. Peppercorn JM, Smith TJ, Helft PR, Debono DJ, Berry SR, Wollins DS, Hayes DM, Von Roenn JH, Schnipper LE. American Society of Clinical O. American society of clinical oncology statement: toward individualized care for patients with advanced cancer. J Clin Oncol. 2011;29(6):755-60.

3. Prigerson HG, Bao Y, Shah MA, Paulk ME, LeBlanc TW, Schneider BJ, Garrido MM, Reid MC, Berlin DA, Adelson KB, et al. Chemotherapy Use, Performance Status, and Quality of Life at the End of Life. JAMA oncology. 2015;1(6):778-84

4. Swetz KM, Smith TJ. Palliative chemotherapy: when is it worth it and when is it not? Cancer J. 2010;16(5):467-72.

5. Koedoot CG, de Haan RJ, Stiggelbout AM, Stalmeier PF, de Graeff A, Bakker PJ, de Haes JC. Palliative chemotherapy or best supportive care? A prospective study explaining patients' treatment preference and choice. $\mathrm{Br} J$ Cancer. 2003:89(12):2219-26.

6. Earle CC, Neville BA, Landrum MB, Ayanian JZ, Block SD, Weeks JC. Trends in the aggressiveness of cancer care near the end of life. J Clin Oncol. 2004; 22(2):315-21.

7. Oostendorp LJ, Stalmeier PF, Pasker-de Jong PC, Van der Graaf WT, Ottevanger PB. Systematic review of benefits and risks of second-line irinotecan monotherapy for advanced colorectal cancer. Anticancer Drugs. 2010;21(8):749-58

8. Oostendorp LJ, Stalmeier PF, Donders AR, van der Graaf WT, Ottevanger PB. Efficacy and safety of palliative chemotherapy for patients with advanced breast cancer pretreated with anthracyclines and taxanes: a systematic review. Lancet Oncol. 2011;12(11):1053-61.

9. Porzsolt F, Tannock I. Goals of palliative cancer therapy. J Clin Oncol. 1993; $11(2): 378-81$.

10. Wright AA, Zhang B, Keating NL, Weeks JC, Prigerson HG. Associations between palliative chemotherapy and adult cancer patients' end of life care and place of death: prospective cohort study. BMJ. 2014;348:g1219.

11. Blinman $P$, King M, Norman R, Viney R, Stockler MR. Preferences for cancer treatments: an overview of methods and applications in oncology. Ann Oncol. 2012:23(5):1104-10.

12. Kadakia KC, Moynihan TJ, Smith TJ, Loprinzi CL. Palliative communications: addressing chemotherapy in patients with advanced cancer. Ann Oncol. 2012;23(Suppl 3):29-32.

13. El-Jawahri A, Traeger L, Park ER, Greer JA, Pirl WF, Lennes IT, Jackson VA, Gallagher ER, Temel JS. Associations among prognostic understanding, quality of life, and mood in patients with advanced cancer. Cancer. 2014; 120(2):278-85.

14. Weeks JC, Catalano PJ, Cronin A, Finkelman MD, Mack JW, Keating NL, Schrag D. Patients' expectations about effects of chemotherapy for advanced cancer. N Engl J Med. 2012;367(17):1616-25.

15. Helft PR. Necessary collusion: prognostic communication with advanced cancer patients. J Clin Oncol. 2005;23(13):3146-50.

16. The AM, Hak T, Koeter G, van Der Wal G. Collusion in doctor-patient communication about imminent death: an ethnographic study. BMJ. 2000; 321(7273):1376-81.

17. Furber L, Cox K, Murphy R, Steward W. Investigating communication in cancer consultations: what can be learned from doctor and patient accounts of their experience? Eur J Cancer Care (Engl). 2013;22(5):653-62.

18. Hancock K, Clayton JM, Parker SM, Wal der S, Butow PN, Carrick S, Currow D, Ghersi D, Glare P, Hagerty R, et al. Truth-telling in discussing prognosis in advanced life-limiting illnesses: a systematic review. Palliat Med. 2007:21(6):507-17.

19. Butow PN, Dowsett S, Hagerty R, Tattersall MH. Communicating prognosis to patients with metastatic disease: what do they really want to know? Support Care Cancer. 2002;10(2):161-8.

20. Stacey D, Bennett CL, Barry MJ, Col NF, Eden KB, Holmes-Rovner M, Llewellyn-Thomas H, Lyddiatt A, Legare F, Thomson R. Decision aids for people facing health treatment or screening decisions. Cochrane Database Syst Rev. 2011;10:CD001431.

21. de Haes H. Dilemmas in patient centeredness and shared decision making: a case for vulnerability. Patient Educ Couns. 2006;62(3):291-8. 
22. Keating NL, Beth Landrum M, Arora NK, Malin JL, Ganz PA, van Ryn M, Weeks JC. Cancer patients' roles in treatment decisions: do characteristics of the decision influence roles? J Clin Oncol. 2010;28(28):4364-70.

23. Cripe LD, Rawl SM, Schmidt KK, Tong Y, Monahan PO, Rand KL. Discussions of life expectancy moderate relationships between prognosis and anxiety or depression in men with advanced cancer. J Palliat Med. 2012;15(1):99-105.

24. Gattellari M, Voigt KJ, Butow PN, Tattersall MH. When the treatment goal is not cure: are cancer patients equipped to make informed decisions? J Clin Oncol. 2002;20(2):503-13.

25. Sepucha KR, Ozanne EM, Partridge AH, Moy B. Is there a role for decision aids in advanced breast cancer? Med Decis Making. 2009;29(4):475-82.

26. Elit LM, Levine MN, Gafni A, Whelan TJ, Doig G, Streiner DL, Rosen B. Patients' preferences for therapy in advanced epithelial ovarian cancer: development, testing, and application of a bedside decision instrument. Gynecol Oncol. 1996;62(3):329-35.

27. Anderson C, Carter J, Nattress K, Beale P, Philp S, Harrison J, Juraskova I. "The booklet helped me not to panic": a pilot of a decision aid for asymptomatic women with ovarian cancer and with rising CA-125 levels. Int J Gynecol Cancer. 2011;21(4):737-43.

28. Fiset V, O'Connor AM, Evans W, Graham I, Degrasse C, Logan J. Development and evaluation of a decision aid for patients with stage IV non-small cell lung cancer. Health Expect. 2000;3(2):125-36.

29. Leighl NB, Shepherd FA, Zawisza D, Burkes RL, Feld R, Waldron J, Sun A, Payne D, Bezjak A, Tattersall MH. Enhancing treatment decision-making: pilot study of a treatment decision aid in stage IV non-small cell lung cancer. Br J Cancer. 2008;98(11):1769-73.

30. Brundage MD, Feldman-Stewart D, Dixon $P$, Gregg $R$, Youssef $Y$, Davies D, Mackillop WJ. A treatment trade-off based decision aid for patients with locally advanced non-small cell lung cancer. Health Expect. 2000;3(1):55-68

31. Smith TJ, Dow LA, Virago EA, Khatcheressian J, Matsuyama R, Lyckholm LJ. A pilot trial of decision aids to give truthful prognostic and treatment information to chemotherapy patients with advanced cancer. J Support Oncol. 2011;9(2):79-86

32. Chiew KS, Shepherd H, Vardy J, Tattersall MH, Butow PN, Leighl NB. Development and evaluation of a decision aid for patients considering first-line chemotherapy for metastatic breast cancer. Health Expect. 2008;11(1):35-45.

33. Leighl NB, Shepherd HL, Butow PN, Clarke SJ, McJannett M, Beale PJ, Wilcken NR, Moore MJ, Chen EX, Goldstein D, et al. Supporting treatment decision making in advanced cancer: a randomized trial of a decision aid for patients with advanced colorectal cancer considering chemotherapy. J Clin Oncol. 2011;29(15):2077-84.

34. Butler M, Ratner E, McCreedy E, Shippee N, Kane RL. Decision aids for advance care planning: an overview of the state of the science. Ann Intern Med. 2014;161(6):408-18.

35. Green MJ, Levi BH. Development of an interactive computer program for advance care planning. Health Expect. 2009;12(1):60-9.

36. Vogel RI, Petzel SV, Cragg J, McClellan M, Chan D, Dickson E, Jacko JA, Sainfort F, Geller MA. Development and pilot of an advance care planning website for women with ovarian cancer: a randomized controlled trial. Gynecol Oncol. 2013;131(2):430-6.

37. Volandes AE, Levin TT, Slovin S, Carvajal RD, O'Reilly EM, Keohan ML, Theodoulou M, Dickler M, Gerecitano JF, Morris M, et al. Augmenting advance care planning in poor prognosis cancer with a video decision aid: a preintervention-postintervention study. Cancer. 2012;118(17):4331-8.

38. Oostendorp LJ, Ottevanger PB, van der Graaf WT, Stalmeier PF. Assessing the information desire of patients with advanced cancer by providing information with a decision aid, which is evaluated in a randomized trial: a study protocol. BMC Med Inform Decis Mak. 2011;11:9.

39. Oostendorp LJ, Ottevanger PB, van de Wouw AJ, Schoenaker IJ, de Graaf H, van der Graaf WT, Stalmeier PF. Expected survival with and without secondline palliative chemotherapy: who wants to know? Health Expect. 2015; 18(6):2903-14

40. van Tol-Geerdink JJ, Leer JW, van Lin EN, Schimmel EC, Huizenga H, van Daal WA, Stalmeier PF. Offering a treatment choice in the irradiation of prostate cancer leads to better informed and more active patients, without harm to well-being. Int J Radiat Oncol Biol Phys. 2008;70(2):442-8.

41. van Tol-Geerdink JJ, Leer JW, Weijerman PC, van Oort IM, Vergunst $H$, van Lin EN, Alfred Witjes J, Stalmeier PF. Choice between prostatectomy and radiotherapy when men are eligible for both: a randomized controlled trial of usual care vs decision aid. BJU Int. 2013;111(4):564-73.
42. Elwyn G, O'Connor A, Stacey D, Volk R, Edwards A, Coulter A, Thomson R, Barratt $A$, Barry $M$, Bernstein $S$, et al. Developing a quality criteria framework for patient decision aids: online international Delphi consensus process. BMJ. 2006;333(7565):417.

43. O'Connor AM, Stacey D, Entwistle V, Llewellyn-Thomas H, Rovner D, Holmes-Rovner M, Tait V, Tetroe J, Fiset V, Barry M, et al. Decision aids for people facing health treatment or screening decisions. Cochrane Database Syst Rev. 2003;2:CD001431.

44. Puhan MA, Frey M, Buchi S, Schunemann HJ. The minimal important difference of the hospital anxiety and depression scale in patients with chronic obstructive pulmonary disease. Health Qual Life Outcomes. 2008;6:46.

45. Smid DE, Franssen FM, Houben-Wilke S, Vanfleteren LE, Janssen DJ, Wouters EF, Spruit MA. Responsiveness and MCID Estimates for CAT, $C C Q$, and HADS in Patients With COPD Undergoing Pulmonary Rehabilitation: A Prospective Analysis. Journal of the American Medical Directors Association. 2017;18(1):53-8.

46. Chan KS, Aronson Friedman L, Bienvenu OJ, Dinglas VD, Cuthbertson BH, Porter R, Jones C, Hopkins RO, Needham DM. Distribution-based estimates of minimal important difference for hospital anxiety and depression scale and impact of event scale-revised in survivors of acute respiratory failure. Gen Hosp Psychiatry. 2016:42:32-5.

47. Schulz KF, Grimes DA. Multiplicity in randomised trials I: endpoints and treatments. Lancet. 2005;365(9470):1591-5.

48. Zigmond AS, Snaith RP. The hospital anxiety and depression scale. Acta Psychiatr Scand. 1983;67(6):361-70.

49. Groenvold M, Petersen MA, Aaronson NK, Arraras JI, Blazeby JM, Bottomley A, Fayers PM, de Graeff A, Hammerlid E, Kaasa S, et al. The development of the EORTC QLQ-C15-PAL: a shortened questionnaire for cancer patients in palliative care. Eur J Cancer. 2006;42(1):55-64.

50. Lerman C, Trock B, Rimer BK, Jepson C, Brody D, Boyce A. Psychological side effects of breast cancer screening. Health Psychol. 1991;10(4):259-67.

51. Watson M, Greer S, Young J, Inayat Q, Burgess C, Robertson B. Development of a questionnaire measure of adjustment to cancer: the MAC scale. Psycho Med. 1988;18(1):203-9.

52. Deber RB, Kraetschmer N, Irvine J. What role do patients wish to play in treatment decision making? Arch Intern Med. 1996;156(13):1414-20.

53. Whelan TJ, Levine MN, Gafni A, Lukka H, Mohide EA, Patel M, Streiner DL. Breast irradiation postlumpectomy: development and evaluation of a decision instrument. J Clin Oncol. 1995;13(4):847-53.

54. Stalmeier PF, Roosmalen MS, Verhoef LC, Hoekstra-Weebers JE, Oosterwijk JC, Moog U, Hoogerbrugge N, van Daal WA. The decision evaluation scales. Patient Educ Couns. 2005:57(3):286-93.

55. Armitage CJ, Conner M. Efficacy of the Theory of Planned Behaviour: a meta-analytic review. Br J Soc Psychol. 2001;40(Pt 4):471-99.

56. Vodermaier A, Millman RD. Accuracy of the Hospital Anxiety and Depression Scale as a screening tool in cancer patients: a systematic review and metaanalysis. Support Care Cancer. 2011;19(12):1899-908.

57. Smith TJ, Dow LA, Virago E, Khatcheressian J, Lyckholm LJ, Matsuyama R. Giving honest information to patients with advanced cancer maintains hope. Oncology (Williston Park). 2010;24(6):521-5.

58. Neuman HB, Charlson ME, Temple LK. Is there a role for decision aids in cancer-related decisions? Crit Rev Oncol Hematol. 2007;62(3):240-50.

59. Stacey D, Samant R, Bennett C. Decision making in oncology: a review of patient decision aids to support patient participation. CA Cancer J Clin. 2008;58(5):293-304.

60. O'Brien MA, Whelan TJ, Villasis-Keever M, Gafni A, Charles C, Roberts R, Schiff S, Cai W. Are cancer-related decision aids effective? A systematic review and meta-analysis. J Clin Oncol. 2009;27(6):974-85.

61. Brom L, Pasman HR, Widdershoven GA, van der Vorst MJ, Reijneveld JC, Postma TJ, Onwuteaka-Philipsen BD. Patients' preferences for participation in treatment decision-making at the end of life: qualitative interviews with advanced cancer patients. PLoS ONE. 2014;9(6):e100435.

62. Matsuyama R, Reddy S, Smith TJ. Why do patients choose chemotherapy near the end of life? A review of the perspective of those facing death from cancer. J Clin Oncol. 2006;24(21):3490-6.

63. Brom L, De Snoo-Trimp JC, Onwuteaka-Philipsen BD, Widdershoven GA, Stiggelbout AM, Pasman HR. Challenges in shared decision making in advanced cancer care: a qualitative longitudinal observational and interview study. Health Expect. 2017;20(1):69-84. 
64. Grunfeld EA, Maher EJ, Browne S, Ward P, Young T, Vivat B, Walker G, Wilson C, Potts HW, Westcombe AM, et al. Advanced breast cancer patients' perceptions of decision making for palliative chemotherapy. J Clin Oncol. 2006;24(7):1090-8.

65. Kiely BE, McCaughan G, Christodoulou S, Beale PJ, Grimison P, Trotman J, Tattersall MH, Stockler MR. Using scenarios to explain life expectancy in advanced cancer: attitudes of people with a cancer experience. Support Care Cancer. 2013;21(2):369-76

Submit your next manuscript to BioMed Central and we will help you at every step:

- We accept pre-submission inquiries

- Our selector tool helps you to find the most relevant journal

- We provide round the clock customer support

- Convenient online submission

- Thorough peer review

- Inclusion in PubMed and all major indexing services

- Maximum visibility for your research

Submit your manuscript at www.biomedcentral.com/submit 